\title{
QUALIDADE DO LIVRO DIDÁTICO: DOS CRITÉRIOS DA LITERATURA ACADÊMICA AOS DO PROGRAMA NACIONAL DO LIVRO DIDÁTICO
}

\author{
THE QUALITY OF THE TEXTBOOK: FROM THE \\ CRITERIA OF ACADEMIC LITERATURE TO THOSE \\ OF THE NATIONAL PROGRAM OF TEXTBOOKS \\ LA QUALITÉ DU LIVRE DIDACTIQUE: DES CRITÈRES DE \\ LA LITTÉRATURE ACADÉMIQUE À CEUX DU \\ PROGRAMME NATIONAL DU LIVRE DIDACTIQUE \\ CALIDAD DEL LIBRO DIDÁCTICO: DE LOS CRITERIOS DE \\ LA LITERATURA ACADÉMICA A LOS DEL PROGRAMA \\ NACIONAL DEL LIBRO DIDÁCTICO \\ Mary Rangel *
}

\section{RESUMO}

Este estudo foi feito no interesse de oferecer aos educadores uma sintese analítica de enfoques de livros didáticos, conforme se apresentam na literatura acadêmica e nos termos de guias e catálogos atuais do Programa Nacional do Livro Didático - PNLD/2005. Assim, o encaminhamento do texto iniciou-se por percorrer a literatura, considerando alguns dos estudos criticos (social, histórica e politicamente situados) sobre os livros didáticos. Seguiu-se a essa revisão a sintese analitica das publicações do PNLD/2005, procurando-se, principalmente, observar parâmetros básicos e comuns a diversas áreas de conhecimento. Na consideração final do estudo, observam-se aspectos comuns da literatura e das publicaçôes do PNLD/2005, ressaltando-se a importância de que se preserve a autonomia de escolha, de forma coletiva, fundamentada e consciente, dos professores, de acordo com o projeto político-pedagógico e as circunstâncias das escolas.

Palavras-chave: Livros didáticos. Critérios de qualidade. Literatura acadêmica. Programa Nacional do Livro Didático.

* Doutora em Educação Brasileira pela Universidade Federal do Rio de Janeiro (UFRJ, 1990). Professora Titular de Didática da Universidade Federal Fluminense (UFF, 1994). Professora Titular de Ensino-Aprendizagem da Universidade do Estado do Rio de Janeiro (UERJ, 1995). Pós-Doutora em Psicologia Social pela Pontifícia Universidade Católica (PUC/SP, 1998). Pesquisadora do CNPq (mrangel@abel.org.br). 


\section{DA LITERATURA ACADÊMICA A PUBLICAÇÕES DO PROGRAMA NACIONAL DO LIVRO DIDÁTICO/2005: A ATENÇÃO A CRITÉRIOS DE QUALIDADE}

A qualidade do livro didático é uma questão que se insere no âmbito acadêmico e de políticas públicas; assim, a sua análise remete ao estudo da literatura e aos termos atuais do Programa Nacional do Livro Didático, em publicações destinadas às escolas, com orientaçōes para a escolha de livros em 2005.

A revisão da literatura sobre essa questão, observando estudos significativos pela afinidade de critérios e pela consideração acadêmica, permite observar a atenção a conceitos, a valores de acolhimento à pluralidade e a princípios de cidadania, rejeitandose estigmas e preconceitos.

Nessa perspectiva, volta-se a Bonazzi e Eco (1980), quando, ao fazerem a crítica a textos de livros que apresentam o mundo de forma equivocada e fantasiosa, propóem alternativas de leituras, como as de jornais, romances de aventuras, histórias em quadrinhos, fatos vivenciados pelos alunos e trazidos por eles à sala de aula, textos que esses próprios alunos podem produzir, ou entrevistas que possam realizar.

Desse modo, em Mentiras que Parecem Verdades, os autores reúnem textos de origem italiana destinados às primeiras leituras, ou seja, que introduzem crianças no ato de ler, com interesse e com uma postura e visão crítica, e situados do mundo real, questionando-se, então, textos ingênuos, que se distanciam dos fatos, escondendo-os sob um estofo de fantasias.

A ideologia e suas intenções de submissão do pensamento são focalizadas, podendo-se fazer um paralelo entre textos italianos, que enfeitam com "pílulas douradas" as questōes concretas do cotidiano, e textos brasileiros, que apresentam, da mesma forma, "mentiras que parecem verdades" (BONAZZI; ECO, 1980, p. 2).

E a proposta de análise crítica e permanente dos livros didáticos brasileiros associa-se à ênfase não só em novas alternativas de fontes de leitura, mas também na ampliação de bibliotecas escolares que ofereçam essas fontes, incluindo as que circulam, cotidianamente, nos meios de comunicação social e as produzidas e organizadas por professores e alunos.

Continuando a crítica ao escamoteamento da realidade e sua mitologização, os autores observam nos livros fantasiosos a reprodução de modelos tradicionais de pensamento que mantêm o mesmo discurso e a mesma ideologia, conservadores do estado desigual das relaçõos e oportunidades sociais.

No caso brasileiro, lembram-se as falácias ou mitos de riqueza, exuberância, cordialidade e paz, de modo que o amarelo simboliza o ouro, o azul a paz e o verde as matas abundantes, no intuito de formar uma "consciência cívica" de um país idealizado, cuja bandeira colorida exaltasse um sentimento positivo, incondicional. Embora essa visão mítica não tenha resistido ao tempo e à vivência de problemas concretos, ainda persiste a preocupação com ilusões, escritas e impressas, transformadas em objetos de estudo nas escolas.

Por isso, Eco (apud BONAZZI; ECO, 1980, p. 15) faz a sua antologia, contrapondo às idéias enganosas questôes instigantes à crítica e à visão mais ampla dos contextos a que os textos se referem. E, nessa leitura crítica, instiga-se também o leitor ao enfrentamento de problemas, que são seus, da sociedade, das decisóes e compromissos políticos. 
Os livros de leitura falam dos pobres, do trabalho, dos heróis e da Pátria, da importância e da seriedade da escola, da variedade das raças e povos que habitam a terra, da família, da religião, da vida cívica, da história humana, da língua italiana, da ciência, da técnica, do dinheiro e da caridade. Não se referem, então, aos problemas reais que o jovem, uma vez maduro, deverá enfrentar e sobre os quais deverá tomar uma atitude? (Ibid, p.15).

Nessa mesma perspectiva, Pacheco (1983) faz a análise de exercícios propostos em livros didáticos, destacando a importância do raciocínio crítico, vinculado à realidade $\mathrm{e}$ ao desenvolvimento da possibilidade de criação, para além da reprodução de idéias.

Balzan (1983, p. 9), ao prefaciar Pacheco, observa que a sua abordagem, no campo dos estudos da física, atende ao interesse da superação de exercícios que induzem à repetição de noções, por outros que mobilizem níveis mais elaborados de raciocínios. Essa superação também poderá ser a de “...mecanismos de fuga que nossa juventude vem visando no sentido de não assumir sua própria aprendizagem”.

O campo da Física é especialmente fértil a reflexôes sobre a importância da atitude e interesse investigativos, de modo que o aluno possa ultrapassar fórmulas prontas e predeterminadas, para entender o conhecimento em seus fatores e processos e suas possibilidades de encaminhar novas descobertas.

Esses princípios remetem a Bruner (apud PACHECO, 1983), quando enfatiza a importância de que o aluno aprenda, mais que o conteúdo da Física, o comportamento de um pesquisador nesse campo e, portanto, exercite as indagações, a demonstração, a experimentação, situando-as na dinâmica da vida, em seu movimento, condições e apelos reais.

Concomitante a essa mesma discussão, associa-se a má qualidade do livro à desqualificação do magistério e correspondentes níveis salariais e precariedade de recursos destinados à educação.

Lembram-se, também, os trabalhos da Unicamp em diversas áreas de conhecimento, nas quais a preocupação com livros didáticos se assemelha nos aspectos da ênfase aos critérios de construção e uso do livro didático, privilegiando-se a criação e as percepções críticas, amplas e situadas dos conteúdos (Ibidem).

Participando desse mesmo movimento e observando o especial destaque, nos livros de Física, aos exercícios, como situações de desenvolvimento de raciocínios e assimilação de conceitos, Pacheco (1983) aplica a taxionomia de Bloom para classificar esses exercícios e os níveis de elaboração de conhecimento proporcionados aos alunos. Assim, examinando livros adotados de 1976 a 1978, a autora estuda tendências relativas ao conteúdo, habilidades e níveis cognitivos requeridos pelos exercícios.

A constatação de que os professores não optavam por livros específicos de exercícios, mas sim por aqueles que continham também textos, cujas informaçôes os introduziam e determinavam sua formulação, corroborou o entendimento de que a análise dos livros de Física não poderia prescindir da análise dos seus exercícios.

Assim, pôde-se verificar, numa amostra considerada significativa, que os raciocínios empregados na resolução dos exercícios mantinham-se, predominantemente, num estágio descritivo, com pouca relação a fenômenos ou processos da Física e às suas aplicações, limitando-se, portanto, aos planos de descrição e compreensão. 
Esse resultado de pesquisa permite também notar a possível relação entre o tratamento dos conteúdos nos livros didáticos e o seu tratamento metodológico no ensino-aprendizagem. A relação pode se dar pelo fato de que livro, ensino, aprendizagem, metodologias, têm condicionantes comuns no sistema socioeducacional que podem induzir opções e práticas.

Contudo, o critério de seleção e uso de livros, para que se tornem recursos e instrumentos de reelaboração pessoal e social de conceitos, inclui, sem dúvida, a atenção a níveis de leitura e raciocínios que os transportem às situaçôes reais do cotidiano.

Nesse sentido, é importante que as leituras e exercícios propiciem níveis de informação, compreensão, aplicação, análise, através dos quais se realiza a transposição didática do conhecimento às situações "concretas e reais do cotidiano":

... Para que isso ocorra, é necessário que os problemas propostos aos alunos tenham características tais que os fenômenos físicos neles envolvidos se refiram ao que há de concreto e real dentro do cotidiano do educando, muito embora devam exigir tratamentos em diferentes níveis de abstração (PACHECO, 1983, p. 124).

Da mesma forma, na perspectiva de inserção no contexto mais amplo do sistema educacional e suas implicaçôes socioculturais, observando, no valor pedagógico, a sua importância como recurso de ensino-aprendizagem, Freitag, Costa e Motta (1997) discutem o livro didático.

Essa discussão fundamentou-se numa pesquisa que se destinou à configuração do estado da arte do livro didático no Brasil, percorrendo diversas fontes, como revistas, acervo de bibliotecas, catálogos de teses, produçōes de programas de pós-graduação e de núcleos de pesquisa. No traçado do estado da arte, focalizaram-se aspectos históricos, políticos, econômicos, assim como de conteúdo, uso e contexto, especialmente da alfabetização e da leitura no primeiro segmento do ensino fundamental.

Observa-se, então, a falta de uma história, no sentido de uma construção participativa da comunidade acadêmica, prevalecendo uma sucessão de leis, decretos e medidas normativas, acentuados a partir dos anos 30, de uma forma pouco articulada e fundamentada. Essa observação leva também a constatar a influência da estrutura política nos termos e propostas da legislação e suas menções ao livro didático.

Em 1937 foi criado o Instituto Nacional do Livro (INL), integrando o Ministério da Educação (MEC). O INL incluía a coordenação de atividades referentes ao livro didático, assumindo a incumbência de desenvolver ações relacionadas a convênios, para efeito de produção e distribuição de livros.

O Decreto-Lei 1.006, de 30 de dezembro de 1938, criou a Comissão Nacional do Livro Didático (CNLD) e trouxe a sua primeira definição normativa:

Art. $2^{\circ}[\ldots]$

$\$ 1^{\circ}$ - Compêndios são livros que exponham total ou parcialmente a matéria das disciplinas constantes dos programas escolares;

$\$ 2^{\circ}$ - Livros de leitura de classe são livros usados para leitura dos alunos em aula; tais livros também são chamados de livros de texto, livro-texto, compêndio escolar, livro escolar, livro de classe, manual, livro didático (OLIVEIRA, apud FREITAG; COSTA; MOTTA, 1997, p. 13). 
Essas e outras definiçōes da CNLD correspondiam às suas funções de controle, avaliação e autorização de livros, cujos termos permitem notar a prevalência de parâmetros políticoideológicos sobre critérios didáticos, tanto que, dos 11 critérios apontados como impeditivos de autorização, apenas cinco referiam-se a questōes didáticas. Apesar da crítica e da suspeita de manipulação comercial, a CNLD persiste até os anos 60.

$\mathrm{Na}$ década de 60, a partir dos acordos MEC/USAID, é criada a Comissão do Livro Didático (Colted), visando a expansão de publicaçōes e de bibliotecas. A Colted também admite a crítica de controle de influências ideológicas e ausência de participação, autonomia do pensamento e ação de educadores brasileiros.

Em 1968, a destinação política do livro a crianças "carentes" se explicita, com mais clareza, nos termos do Programa do Livro Didático - Ensino Fundamental (PLIDEF), a qual se sucedeu o Programa do Livro Didático para o Ensino Médio e Supletivo (PLIDEM e PLIDESU), ambos preservando a intenção de atender às camadas de maior "carência" socioeconômica. A Fundação de Assistência ao Estudante (FAE), criada em 1983, participa desse mesmo movimento, procurando alcançar a pré-escola e o ensino de $1^{\circ}$ e $2^{\circ}$ graus. Nas críticas a esses programas destacam-se as observaçōes de assistencialismo e centralização de decisões.

Em 1985, formula-se nova legislação, no intuito de promover a descentralização administrativa do Programa Nacional do Livro Didático e privilegiar a escolha do livro, com autonomia, pelos professores. Nessa política, insere-se também o critério de durabilidade do livro, superando a proposta do livro descartável.

Assim, fatores políticos estão intimamente vinculados aos históricos e aos legais na evolução das propostas do livro didático, podendo-se destacar, nas discussóes que movem essa evolução, os aspectos da centralização de decisões, em confronto com a descentralização e a participação da comunidade acadêmica, associada à ênfase na superação de controles ideológicos e influências externas, que, ao mesmo tempo em que assumem uma postura assistencialista, prejudicam a autonomia do pensamento, produção e editoração brasileiras.

Outro aspecto que evolui, política e historicamente, é o da atenção à qualidade dos livros e à sua durabilidade. Nesse sentido, ressalta-se a importância de análises criteriosas e participativas, que envolvam os educadores e considerem fundamentos sociais e didáticopedagógicos, para efeito de uma avaliação qualitativa, legitimada pelo seus princípios e processos.

Assim, a avaliação dos livros considera fatores históricos, sociais, políticos, e inclui, também, questionamentos a fatores de ordem econômica, que interferem na má qualidade material. Quanto ao conteúdo, permanece a preocupação com camuflagens ideológicas, como as que, "...procuram disfarçar o estudo em brincadeira, a tarefa em jogo, a lição em travessura” (LINS, apud FREITAG; COSTA; MOTTA, 1997, p. 63).

Desse modo, sublinha-se a crítica a aspectos ideológicos da composição dos textos e recomenda-se a consideração às circunstâncias reais do cotidiano e à oferta de um conteúdo que dê condiçóes ao aluno de alcançar a "universalidade cultural":

A universalidade cultural, expressa na linguagem culta e nos padrões estéticos da grande literatura, é, a nosso ver, o que de melhor a escola pública pode oferecer à criança carente para que ela adquira as condiçôes cognitivas e lingüísticas de sair de sua condição de classe: condições necessárias, embora obviamente não suficientes (Ibid, p. 98). 
As questões anteriores são também levadas em conta nas análises do uso do livro didático, notando-se a predominância das atenções normativas e de pesquisas ao uso pelo professor, em relação ao uso pelo aluno, ressaltando-se, portanto, a necessidade de enfatizar esse aspecto. E, além desse aspecto, a ser recomendado na discussão do uso do livro e na produção de conhecimento a seu respeito, é relevante, ainda, levar em conta a compreensão de que o uso do livro não é condicionante ou determinante da metodologia de ensino-aprendizagem, mas apenas um recurso ou instrumento.

Desse modo, privilegia-se a compreensão ampla e fundamentada de métodos de ensinoaprendizagem, sem condicioná-los aos livros adotados, mas associando-os à competência do professor, ao conteúdo e ao contexto, observando-se também a importância de que se considerem fatores relacionados a processos sociocognitivos, necessidades, conhecimento anterior, prazer e interesses do aluno.

Nessa perspectiva, destaca-se, também, a importância da escolha dos livros pelos professores, considerando sua experiência e convicções, seu contexto e circunstâncias (da escola, dos alunos), de modo que as propostas formais não se constituam em condicionantes exclusivos e evitando-se que a discussão seja substituída pela acomodação ou pelo conformismo.

Assim, Freitag, Costa e Motta (1997) fazem uma abordagem ampla do livro didático, demonstrando a sua complexidade e a concorrência de fatores - históricos, sociais, políticos, epistemológicos - que interferem na sua análise.

Essa visão ampla encontra respaldo em perspectivas como as de Apple (1986), quando associa o debate do trabalho docente e de textos de estudo às questōes econômicas, de classe e de gênero.

Nos livros didáticos, materializam-se condiçōes e referências ao ensino-aprendizagem, assim como à compreensão e definições de elementos da cultura. Por isso, os livros tornam-se foco de interesses políticos e ideológicos, por seu potencial de influência na maneira de entender e conduzir a apropriação do conhecimento e da cultura, na escola e na sociedade. Esse processo pode estar associado à submissão cultural.

A submissão sociocultural contém fatores de mercado, que se associam aos ideológicos, de modo que a indústria de produção e comercialização de livros se sobreponha à construção crítica, fundamentada, consciente e autônoma do conhecimento, assim como à escolha de livros com essa mesma orientação.

Com preocupaçōes dessa natureza, denunciam-se processos burocratizados e estruturas formais, normatizadas e pré-definidas de decisōes, que padronizam critérios e propostas e direcionam a escolha e a compra de livros.

Livro é expressão de bem cultural; escolhê-lo e adotá-lo são procedimentos que requerem a compreensão da lógica que preside a forma como são produzidos e comercializados, por quem, para quem e com que motivaçôes, além das aparentes, traduzidas em critérios de divulgação e distribuição formalizados, padronizados. Por isso, o que os professores decidem não está imune a interesses econômicos e políticos, movidos por ideologias, pois “...as relações dominantes são continuamente reconstituídas pelas ações que empreendemos e pelas decisões que tomamos em nossas áreas de vida locais" (APPLE, 1986, p. 98).

Aportes dessa natureza estendem a percepção das implicações da escolha de livros didáticos, demonstrando a profundidade e a rede de questôes que essa escolha envolve. 
Trazendo esses aportes para o âmbito de determinadas áreas específicas de conhecimento, encontram-se pesquisas, como as de Pacheco (1983) e Passini (1998), que auxiliam essa mesma percepção.

Passini (1998), quando focaliza o livro didático de Estudos Sociais, com atenção ao processo de alfabetização cartográfica, assinala que os aspectos de qualidade e utilização remetem a fatores mais amplos, do ponto de vista sociopolítico e econômico.

A autora observa, então, que os questionamentos permanecem associados à adoção de livros cuja qualidade limita-se a elementos materiais, gráficos e com figuras ilustrativas. As editoras se isentam de comprometimento com a qualidade do conteúdo e da adequação metodológica, que ficam a critério dos autores. Segundo, ainda, afirmação das editoras, os professores não têm demonstrado preferência por livros que estimulem análises e respostas pessoais dos alunos, assegurando que a opção tem sido por textos descritivos, acompanhados de questôes nesse mesmo nível.

Assim, os professores optam por livros cujos textos se acompanham de ilustrações, exercícios e indagações, com respostas simples e diretas, além de trazerem também planos de ensino cuja cópia pode ser encaminhada à direção da escola, atendendo a um requisito administrativo. Outro aspecto a ser considerado é o da correção dos conceitos, notandose, com frequiência, erros ou defasagens nas definições, cuja leitura repetitiva não admite análise ou discussão. Essa situação é especialmente grave quando se considera que o livro didático seja, talvez, uma das poucas fontes de conhecimento às quais os alunos de camadas populares tenham acesso.

Desse modo, o aluno pode ser habituado a descrever e aceitar informaçôes, sendo pouco ou nada estimulado a confrontá-las com fatos reais, o que também solicitaria uma leitura associativa, contextualizada e interpretativa.

O livro, com conteúdo distanciado dos fatos e com um tratamento metodológico limitador do pensamento e do nível de leitura, ocupa o lugar de textos diversificados, nos quais professores e alunos possam encontrar opiniōes diversas, estimulantes de raciocínios mais elaborados e críticos.

É necessário que o livro didático seja produzido e escolhido com critérios de correção de conteúdo e linguagem, adequados ao estágio de escolaridade dos alunos, estimulantes do seu pensamento e das associaçōes com circunstâncias reais, sociopolíticas, econômicas e sociais, em que o conhecimento geográfico, essencialmente contextualizado, se insere (PASSINI, 1998).

A consistência do conteúdo, a atenção a conceitos, interpretados e discutidos com referências de realidade, são, portanto, ênfases de pesquisas que se acentuam nos anos 80 , consolidando perspectivas mais amplas de análise do conteúdo dos livros e seu tratamento metodológico. Assim, destacam-se os relatórios de Alves (1986), Azevedo (1981), Balau (1982) e outros que fundamentam e estimulam o enfrentamento da qualidade social e pedagógica dos livros didáticos.

Nessa revisão de alguns dos estudos, cuja afinidade e coerência crítica estabelecem tendências atuais de análise de livros didáticos, encontram-se elementos que encaminham a leitura de propostas do Programa Nacional do Livro Didático - PNLD/2005 (BRASIL, 2004a, 2004b, 2004c, 2004d, 2004e) e Programa Nacional do Livro para o Ensino Médio - PNLEM/2005 (BRASIL, 2004f, 2004g). 
Em publicações do PNLD/2005 referentes a História, Geografia, Matemática e Ciências, assim como nas publicações do PNLEM/2005, referentes a Língua Portuguesa e Matemática, pode-se constatar a presença de critérios de análise de livros consolidados na literatura crítica, assim como a ressalva, comum a todas as áreas de conhecimento, no sentido da compreensão de que o livro é um, mas não o único recurso de ensino-aprendizagem, e de que a reflexão fundamentada e a decisão dos professores, assim como a adequação da escolha ao projeto das escolas e aos interesses dos alunos, devam ser preservados.

Assim, por exemplo, no Volume 5, Guia de livros didáticos/2005 para $5^{\mathrm{a}}$ a $8^{\mathrm{a}}$ séries, encontram-se resenhas de coleçōes recomendadas para a área de História, ressalvando-se o requisito da compatibilidade com o projeto da escola, interesses dos alunos, reflexões e decisões fundamentadas dos professores. A avaliação exclui publicações com erros ou defasagem de conceitos, com tratamento metodológico em desacordo com a proposta que se apresenta no livro, assim como elementos que contenham discriminações ou preconceitos. Nos livros recomendados, observam-se aspectos positivos, como o da correção, atualidade e contextualização de conceitos, e negativos, como o do tratamento predominantemente fatual, conteudista e o de exercícios dissociados do contexto do aluno e pouco estimulantes ao raciocínio e à criatividade (BRASIL, 2004c).

No Guia com coleçôes avaliadas e aprovadas na área de Geografia no PNLD/2005, reafirma-se que o livro não é o único material, mas apenas um dos recursos ou referências ao ensino-aprendizagem. $\mathrm{Na}$ apropriação do conhecimento geográfico, ressaltam-se critérios como o da compreensão das relações entre sociedade e meio ambiente, entre fatos do cotidiano e os conceitos e linguagens dos textos, observando-se, nessa relação, os valores de cidadania e de acolhimento à pluralidade.

Entre os critérios eliminatórios de livros de Geografia, destaca-se a incoerência entre o tratamento metodológico e a proposta apresentada, a incorreção de conceitos e informações, e a desconsideração a valores de cidadania (BRASIL, 2004b).

No Guia de Ciências, consideram-se os aspectos positivos da abordagem abrangente de conteúdos, de modo a introduzir o aluno em diferentes áreas do conhecimento científico, o estímulo ao raciocínio, a consideração a fatos e fenômenos vivenciados no cotidiano, a pertinência de ilustrações ao conteúdo, a indicação de experimentos que incluem atividades práticas, de execução simples e com materiais acessíveis, esclarecendo-se procedimentos de segurança.

Foram critérios excludentes a falta de abrangência, atualização e correção conceitual, a inadequação metodológica, o descompromisso com valores de cidadania ou com orientações que preservem a integridade física e segurança dos alunos (BRASIL, 2004a).

Quanto ao Guia de Língua Portuguesa em nível de $5^{\mathrm{a}}$ à $8^{\mathrm{a}}$ série, os princípios e critérios específicos da área recomendam um tratamento metodológico abrangente, que contemple os objetivos do ensino fundamental em leitura, produção de textos, linguagem oral, conhecimentos lingüísticos e padrões gramaticais aplicados ao discurso. A natureza do material textual é também observada, recomendando-se, entre outros aspectos, variedade de gêneros, tipos, contextos sociais, assim como a presença de dialetos, de registros lingüísticos diversificados, de textos literários, de textos complementares para atividades de leitura, a diversificação temática, ressaltando-se também a importância da atenção à autenticidade e integralidade dos textos. 
Quanto às atividades de leitura e compreensão de textos, encontra-se a ênfase em processos de interlocução, interpretação, reconstrução de sentidos, exploração de estratégias diversificadas de leitura, exploração da textualidade e variedade de exercícios.

Incluem-se, ainda, critérios relativos a condições de produção de textos, escritos e orais, a serem explicitados claramente aos alunos. Nesse sentido, os livros devem contribuir para a construção da textualidade, com coerência e estilo adequado ao gênero e às circunstâncias ou situações a serem contempladas no texto, atendendo, também, a padrôes ortográficos.

$\mathrm{O}$ trabalho sobre conhecimentos lingüísticos deve favorecer o desenvolvimento de condiçôes de uso da língua em níveis de reflexão metalingüística, de análise, generalização, aplicação, observando-se aspectos de qualidade dos conteúdos, a exemplo dos fonoortográficos, morfossintáticos, semânticos, textuais e discursivos (BRASIL, 2004d).

No Guia de Matemática (PNLD/2005 - 5a à $8^{a}$ série), apresentam-se, além das resenhas das obras aprovadas, os "critérios comuns a todas as áreas disciplinares", apontando-se, como "critérios eliminatórios", a "correção dos conceitos e informações básicas", a "correção e adequação metodológicas" e a "contribuição para a construção da cidadania” (BRASIL, 2004e, p. 202-204).

Apontam-se, também, como critérios, embora "não eliminatórios", os "conteúdos adequados à sociedade atual", a "articulação das áreas de aritmética, álgebra, geometria, grandezas e medidas, estatística, probabilidade e combinatória”, o estímulo ao uso da intuição, as associações a fatos do dia-a-dia, no interesse de desenvolver níveis de raciocínios abstratos a partir de situaçōes concretas (Ibid, p. 204).

É interessante, no PNLD/2005, a menção ao nível de raciocínio do aluno, "subestimado" ou, ao contrário, "superestimado" pelo texto:

$\mathrm{O}$ texto subestima o aluno quando desconsidera a riqueza e variedade de experiências e interesses que ele traz para a escola. $\mathrm{O}$ aluno é também subestimado com a apresentação de situaçôes, problemas e atividades que não exercitam sua imaginação e criatividade. $\mathrm{O}$ aluno é superestimado quando o texto o supõe já capaz de um raciocínio lógico-dedutivo plenamente desenvolvido e apresenta a Matemática de um ponto de vista essencialmente formal e sistematizado (Ibid, p. 205).

Ainda, no Guia de Matemática do PNLD/2005, para 5a à $8^{a}$ série, encontra-se uma ressalva, especialmente oportuna, relativa ao princípio da contextualização, bastante atual e recorrente na avaliação de currículos e livros didáticos. Essa ressalva refere-se à artificialidade de exercício formulados no intuito de "forçar" a aplicação de conceitos a fatos do cotidiano, porém de maneira pouco significativa e consistente. Assim, o Guia recomenda que a contextualização dos exercícios seja feita naturalmente, no âmbito da própria Matemática, em lugar de forçá-la em outras situações criadas artificialmente.

Pode-se, portanto, constatar, não só no Guia de Matemática, mas também nos das demais áreas, associações entre a qualidade dos livros e a qualidade dos conceitos e seu tratamento metodológico abrangente e contextualizado. Essa tendência pode também ser observada nos catálogos do PNLD/2005.

Os catálogos do PNLEM/2005 incluem, como os Guias do PNLD/2005, uma resenha de livros, cujas análises são introduzidas por fundamentos sociais, curriculares e 
didáticos. Esses catálogos chegam às escolas da rede pública, porém com recomendação de que as escolhas sejam feitas de acordo com a proposta pedagógica da escola e com consenso da equipe docente.

Os catálogos do PNLD/2005 contemplam apenas as áreas de Língua Portuguesa e Matemática, prevendo-se, nos próximos anos, publicações referentes a outras áreas.

$\mathrm{Na}$ apresentação do catálogo do PNLEM/2005 de Língua Portuguesa às escolas, retomam-se as finalidades da formação em nível médio, nos termos da Lei de Diretrizes e Bases da Educação Nacional (BRASIL, 1996) e contemplam-se "capacidades" a serem desenvolvidas no processo de ensino-aprendizagem, como as de "inferir, argumentar, produzir" o conhecimento (BRASIL, 2004f, p. 9). Dessa forma, e considerando o livro como um recurso à ampliação dos trabalhos em sala de aula, o catálogo introduz critérios gerais de avaliação de textos e exercícios, considerados comuns a todas as áreas de conhecimento. Entre esses critérios, incluem-se a correção das informações, conceitos e procedimentos que integram o componente curricular; adequação de sua proposta didático-pedagógica em relação à situação de ensino-aprendizagem e aos objetivos visados; afinidade, sintonia com a legislação e documentos que normatizam e orientam a Educação Nacional.

Aos critérios anteriores, acrescentam-se dois outros que são considerados, não só comuns a todas as áreas, como "eliminatórios" de livros que não os apresentem. Esses critérios são os da correção de conceitos e informaçōes, e o respeito aos princípios de construção e preservação dos valores da vida cidadã. Associados a esses critérios, ressaltam-se a observância de parâmetros legais referentes aos direitos das crianças e dos adolescentes e a rejeição a preconceitos ou privilégios de camadas sociais, assim como à doutrinação religiosa e à publicidade comercial.

São também sinalizados os "papéis do livro no ensino médio", no sentido de ampliarem conhecimentos adquiridos no ensino fundamental, oferecerem informações que auxiliem a inserção do aluno no mercado de trabalho e, ao mesmo tempo, possam constituir-se em apoio à atualização do professor. Essas informaçōes, portanto, devem corresponder aos avanços do conhecimento em cada área específica.

É interessante também levar em conta a "qualidade do livro do professor", de acordo com suas "funções" de:

- Descrever a estrutura geral da obra, explicitando a articulação pretendida entre suas unidades e objetivos específicos de cada uma delas;

- Orientar, com formulaçōes claras e precisas, os manejos pretendidos ou desejáveis do material em sala de aula;

- Sugerir atividades complementares, como projetos, pesquisas, jogos etc.;

- Fornecer respostas ou padróes de respostas para parte das atividades propostas aos alunos;

- Discutir o processo de avaliação da aprendizagem e mesmo sugerir instrumentos, técnicas e atividades;

- Informar e orientar o professor a respeito de conhecimentos atualizados e especializados, indispensáveis à adequada compreensão de aspectos específicos de uma determinada atividade ou mesmo da proposta pedagógica do livro (BRASIL, 2004f, p. 12). 
Assim, o catálogo do PNLD/2005 de Língua Portuguesa aborda critérios que se organizam em temas amplos, semelhantes ao do ensino fundamental, contemplando aspectos de atualidade dos conhecimentos lingüísticos, da gramática aplicada, da metalinguagem, da norma, das relações entre o discurso oral e o escrito, da diversificação de exercícios e de atividades de leitura, da produção de textos e do ensino da literatura. Desse modo, a diversificação de alternativas de textos e atividades e a atenção à proficiência, associadas à qualidade literária dos textos, são especialmente realçadas, observando-se a importância de que todos os aspectos sejam suficientemente esclarecidos nas orientações do manual do professor.

Em síntese, no detalhamento dos critérios que conferem qualidade aos livros de Língua Portuguesa, podem-se notar, em comum, o cuidado com a compreensão ampla (para além de correçôes gramaticais), dinâmica e estimulante do uso oral e escrito da língua, com especial atenção à produção de textos e à diversificação de atividades.

Quanto ao catálogo do PNLD/2005 de Matemática, inicia-se apontando dois critérios de qualidade considerados "comuns" a todas as áreas de conhecimento e, também, "eliminatórios" dos livros que não os apresentem: - a "correção de conceitos e das informaçôes básicas" e o "respeito aos princípios de construção da cidadania". A "coerência e adequação metodológica", embora não se incluam nos critérios "eliminatórios", também são apontados como qualidades comuns a todas as áreas (BRASIL, 2004g, p. 70).

Nos critérios específicos da avaliação de qualidade dos livros de Matemática, destacamse os princípios da abrangência, da diversidade e de aspectos metodológicos.

No critério da abrangência, observa-se que:

Para ser compatível com os objetivos do ensino de Matemática no Ensino Médio, um livro didático deve abranger um amplo espectro de conteúdos nos campos da aritmética, da geometria, da álgebra, das grandezas e medidas, da estatística, das probabilidades e da combinatória (BRASIL, 2004g, p. 71).

No critério da diversidade, observa-se que “...um mesmo conceito matemático pode ser abordado em mais de um dos campos temáticos acima referidos e, mesmo dentro de cada um deles, pode ser tratado de diferentes pontos de vista" (Ibid, p. 71).

Nos aspectos metodológicos, exemplificam-se tipos de abordagens de diversos conteúdos, sempre preservando as articulaçôes e as confluências de conceitos.

Assim, com esse conjunto de observaçōes, que se assemelham na ênfase à consistência e correção de conceitos e em valores sociais que os orientam, chega-se à consideração final deste estudo. 


\section{CONSIDERAÇÃO FINAL}

Considera-se, finalmente, que os Guias do Plano Nacional do Livro Didático/PNLD/2005 (BRASIL, 2004a, 2004b, 2004c, 2004d, 2004e) e os Catálogos do Programa Nacional do Livros para o Ensino Médio/PNLEM/2005 (BRASIL, 2004f, 2004g) afinam-se nas perspectivas e valores que orientam os critérios de avaliação de qualidade dos livros. Esses critérios são formulados contemplando princípios comuns a todas as áreas de conhecimento e princípios específicos da área correspondente aos Guias do PNLD/2005 e aos Catálogos do PNLEM/2005.

Em termos amplos e gerais, podem-se sintetizar, na perspectiva dos critérios comuns e específicos, a ênfase na consistência do conteúdo e na correção de conceitos, enfatizando-se os valores de cidadania que devem orientar a formulação dos textos.

Nos aspectos relativos ao tratamento metodológico, destacam-se princípios de aplicação de conceitos a situações reais do cotidiano e das suas associações e articulações em diversos enfoques, realçando-se, também, a importância da variedade de exercícios e atividades, estimulantes do raciocínio e de níveis menos descritivos e mais elaborados do conhecimento.

Além da afinidade de critérios nos termos das publicações dos Guias do PNLD/2005 e dos Catálogos do PNLEM/2005, pode-se também observar a mesma afinidade com os termos da literatura crítica e suas tendências, especialmente a partir dos anos 80 .

Portanto, nas bases do PNLD/2005 e do PNLEM/2005, encontram-se fundamentos didático-pedagógicos, epistemológicos, curriculares e os aportes críticos, social, histórica e politicamente situados, de análise dos livros didáticos.

Ao concluir este estudo, é importante deixar, para reflexão e atenção dos educadores, o realce do princípio da autonomia da escolha de livros pelas equipes docentes das escolas: uma autonomia que, embora ressalvada nos termos dos Guias e Catálogos do Programa Nacional do Livro Didático, precisa, realmente, ser preservada e praticada.

Assim, coletivamente, reunidos por séries ou ciclos, por disciplinas ou áreas de conhecimento, e considerando o projeto político-pedagógico da escola, seus propósitos e circunstâncias, os professores exercerão, como direito e dever de sua competência, a escolha desse recurso à sua prática de ensino-aprendizagem: o livro didático. Que seja uma escolha fundamentada, autônoma e consciente! 


\section{Referências}

ALVES, Nilda. O cotidiano do livro didático: a articulação do conteúdo e do método nos livros didáticos. Brasília/Rio de Janeiro: Inep/Flacso, 1986. Relatório final. Mimeografado.

APPLE, Michael W. Trabalho docente e textos: economia política das relações de classe e de gênero em educação. Porto Alegre: Artes Médicas, 1986.

AZEVEDO, Janete Maria Lins. Educação e reprodução: o caso do ensino da História do Brasil. Dissertação, 1981 (Curso de Mestrado em Educação). Universidade Federal de Pernambuco.

BALAU, Virgínia Lopes. Texto didático: reflexão sobre análise de conteúdo e análise do discurso.

Dissertação, 1982 (Curso de Mestrado em Educação). Pontifícia Universidade Católica de São Paulo.

BALZAN, Newton. Prefácio. In: PACHECO, Decio. Tarefa de escola. Campinas: Papirus, 1983, p. 9-13.

BONAZZI, Marisa; ECO, Umberto. Mentiras que parecem verdades. São Paulo: Summus, 1980.

BRASIL. Ministério da Educação. Programa Nacional do Livro Didático. Ciências. Volume 1. Guia de livros didáticos 2005. 5a a 8a séries. Brasília: MEC, $2004 \mathrm{a}$.

BRASIL. Ministério da Educação. Programa Nacional do Livro Didático. Geografia. Volume 6. Guia de livros didáticos 2005. 5a a 8a séries. Brasília: MEC, $2004 \mathrm{~b}$.

BRASIL. Ministério da Educação. Programa Nacional do Livro Didático. História. Volume 5. Guia de livros didáticos 2005. 5a a 8a séries. Brasília: MEC, 2004c.

BRASIL. Ministério da Educação. Programa Nacional do Livro Didático. Língua Portuguesa. Volume 2. Guia de livros didáticos 2005. 5a a 8a séries. Brasília: MEC, $2004 \mathrm{~d}$.

BRASIL. Ministério da Educação. Programa Nacional do Livro Didático. Matemática. Volume 3. Guia de livros didáticos 2005. 5a a 8a séries. Brasília: MEC, $2004 \mathrm{e}$.

BRASIL. Ministério da Educação. Catálogo do Programa Nacional do Livro para o Ensino Médio: PNLEM/2005, Língua Portuguesa. Brasília: MEC, $2004 f$.

BRASIL. Ministério da Educação. Catálogo do Programa Nacional do Livro para o Ensino Médio: PNLEM/2005, Matemática. Brasília: MEC, 2004g.

FREITAG, Bárbara; COSTA, Wanderly Ferreira da; MOTTA, Valéria Rodrigues. O livro didático em questão. 3. ed. São Paulo: Cortez, 1997.

PACHECO, Decio. Tarefa de escola. Campinas: Papirus, 1983.

PASSINI, Elza Yazuko. Alfabetização cartográfica e o livro didático: uma análise crítica. Belo Horizonte: Ed. Lê, 1998. 


\title{
The quality of the textbook: from the criteria of academic literature to those of the National Program of Textbooks
}

\begin{abstract}
This study was done in the interest to offer the educators an analytical synthesis of textbooks approaches, as they are presented in academic literature and current Guides and Catalogues of The National Program of Textbooks - NPT/2005. Thus, the orientation followed by this text initiated by covering the literature, considering some of the critical studies on the textbooks (social, historical and politically positioned). An analytical synthesis of the publications of the NPT/2005 followed this review, observing mainly basic and common parameters to the various areas of knowledge. In the final consideration of the study, common aspects found in the literature and in the publications of the NPT/2005 are noted, pointing out the importance of preserving the autonomy in the choice of the teachers, in a collective form, with foundations and consciousness in accordance with the political-pedagogical project and the circumstances of schools.
\end{abstract}

Keywords: Textbooks. Criteria of quality. Academic literature. National Program of Textbooks.

\section{La qualité du livre didactique: des critères de la littérature académique à ceux du Programme National du Livre Didactique}

Résumé

Cette étude a été réalisée dans l'intérêt d'offrir aux éducateurs une synthèse analytique des approches sur les livres didactiques, selon la littérature académique et selon les termes de Guides et Catalogues actuels do Programme National du Livre Didactique - PNLD/2005. De cette façon, le cheminement du texte a commencé par une revision de la littérature, considérant quelques études critiques sur les livres didactiques (situés du point de vue social, historique et politique). Il sen est suivi une revision analitique des publications du PNLD/2005, cherchant principalement à observer les paramètres de base et communs entre la littérature et les publications du PNLD/2005 et mettant en relief l'importance que se préserve l'autonomie de choix des maîtres, de manière collective et consciente, en accord avec le projet politique et pédagogique et les circonstances des écoles.

Mots clefs : Livres didactiques. Critères de qualité. Littérature académique. Programme National du Livre Didactique.

\section{Calidad del libro didáctico: de los criterios de la literatura académica a los del programa nacional del libro didáctico}

Resumen

Este estudio fue hecho con la intención de ofrecer a los educadores una sintesis analítica de enfoques de libros didácticos, conforme se presentan en la literatura académica y en los términos de guias y catálogos actuales del programa nacional del libro didáctico - PNLD/2005. Así, el texto se inició por la literatura, considerando algunos de los estudios críticos (social, histórica y politicamente situados) acerca de los libros didácticos. Siguió a esa revisión la sintesis analítica de las publicaciones del PNLD/2005, buscándose, principalmente, observar parámetros básicos y comunes a diversas áreas de conocimiento. En la consideración final del estudio, se observan aspectos comunes de la literatura y de las publicaciones del PNLD/2005, resaltándose la importancia de que se preserve la autonomía de elección de los profesores, de forma colectiva, fundamentada y conciente, de acuerdo con el proyecto político-pedagógico y las circunstâncias de las escuelas.

Palabras-clave: Libros didácticos. Critérios de calidad. Literatura académica. Programa nacional del libro didáctico.

Recebido: 22.11 .2004

Aceito: 28.03.2005 